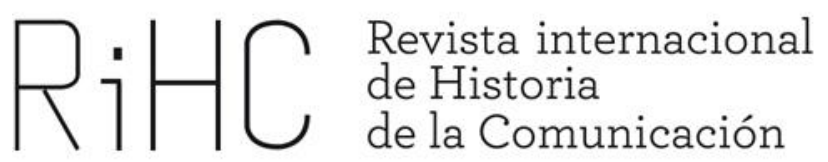

\title{
EL SENSACIONALISMO EN COSTA RICA
}

DOI: http://dx.doi.org/10.12795/RiHC.2015.105.02

Patricia Vega Jiménez

Universidad del Costa Rica

patricia.vega@ucr.ac.cr

Recibido: 29-12-2015

Aceptado: 12-2-2016

Resumen: El objetivo de este texto es analizar históricamente, el proceso evolutivo del periodismo sensacionalista en Costa Rica, un tema descuidado en la historiografía de la comunicación en ese país centroamericano.

El sensacionalismo es tardío en Costa Rica con respecto al desarrollo que tuvo en Estados Unidos. No obstante hubo formas de sensacionalismo y de amarillismo desde principios del siglo XX pero se publicaron de manera aislada y esporádica. Se trataba de notas de accidentes descritos con crudeza, crímenes, suicidios, pleitos callejeros, entre otros.

La prensa con características propias del sensacionalismo y el amarillismo, es un fenómeno de la octava década del siglo XX. Desde el inicio las ventas de esta prensa han sido cuantiosas ocupando el primer lugar en los gustos de las audiencias. Es una prensa popular, consumida principalmente por los sectores populares aunque entre los clientes también se cuentan profesionales, empresarios, académicos, etc.

Palabras clave: prensa, sensacionalismo, Costa Rica, amarillismo.

Abstract: The main objective of this text is to historically analyze the process of evolution of the sensationalist journalism in Costa Rica, a subject that has been pushed 
aside in the historiographies of communication en the aforementioned central American country.

When compared with the development that sensationalism underwent in the United States, it wasn't until later that it arrived to Costa Rica. Nevertheless, there have been found hints of sensationalism dating all the way back to the beginnings of the $X X$ century, which were seldomly and isolatedly published, focused mainly on crudely reported accidents, crimes, suicides, street fights, among others.

Press that has been distinguished by characteristics attributed to sensationalism is a phenomenon that dates from the eighth decade of the XX century. Since it's beginnings, the sales of sensationalist printed press have done very well, occupying the first place in audience preference. It is a popular form of press, consumed mainly by a popular target, even though; professionals, entrepreneurs and academics are among it's clients.

Keywords: Press, sensationalism, sensationalism, Costa Rica

\section{Introducción}

El sensacionalismo y su derivación en el amarillismo, fue relativamente tardío en Costa Rica. Mientras en Estados Unidos los principales medios de comunicación impresos lo perfeccionaban desde mediados del siglo XIX, en Costa Rica se inició con gran timidez a finales de la misma centuria y particularmente en la segunda década del siglo XX. Los periódicos que lo adoptaron fueron los menos pues la prensa política con intereses electorales seguía dominando el mercado.

Desde los años 80 del siglo XIX y aún antes con los penny papers (Schudson, 1978), Joseph Pulitzer en Nueva York había ensayado con éxito el nacimiento y desarrollo del periodismo sensacionalista, haciendo uso de las técnicas que había probado James Gordon Bennett en el New York Herald y Benjamín Henry Day en el New York Sun, que se resumen en una apelación al morbo provocado por el sufrimiento. No obstante la evocación a las sensaciones humanas, "el diario se erigía a sí mismo en el más fiel conocedor de las inquietudes ciudadanas y, en consecuencia, en su más legítimo representante frente a los poderes públicos, por otro, porque liquidaba una de las más decisivas conquistas de la modernidad: la separación entre esfera pública y privada al explotar como noticia cualquier historia dramática de carácter personal o familiar." (García, 1999: 93)

Desde 1833, Benjamín Henry Day logró, gracias a la captación de publicidad, ser el pionero de la prensa barata en los Estados Unidos y en darle a las noticias contenidos humanos. Casi simultáneamente, James Gordon Bennett hacía referencia a los problemas que iban surgiendo, enfatizaba en las informaciones sobre crímenes y le daba a las publicaciones un tono desenfadado pero con noticias documentadas. Incluso utilizó todos los medios a su disposición para obtener las informaciones: 
palomas mensajeras, barcos, ferrocarriles, telégrafo. Se preocupaba por dar noticias recientes, completas y veraces y comentadas con independencia, claridad y libertad, de los acontecimientos. Fue pionero en darle lugar a las noticias políticas, de sucesos, deportes y religión y en sacar una edición especial en domingos.

El periodismo sensacionalista se caracterizó por el uso del formato tabloide, que facilita la lectura, los titulares de varias columnas, el acompañamiento gráfico en el texto, el uso de entradilla, la edición dominical destinada al ocio, la aparición de secciones para mujer, jóvenes, deportes, ficción y las cruzadas sociales: defensor de la causa de los desaparecidos, en una sociedad cargada de migrantes en busca del sueño americano (García, 1999: 92).

Los cambios que evidenció este nuevo periodismo, que nace para satisfacer la demanda de un público cada vez más alfabetizado, de un crecimiento económico y de un desarrollo industrial que captaba cada vez más obreros cuyo referente cultural era la prensa diaria, la mejora en las infraestructuras de comunicación y de los métodos de gestión empresarial, entre otros factores, fueron: competencia por el mercado de lectores, la búsqueda de primicias y exclusivas, el interés por impactar, la incorporación de columnas de opinión, relatos de ficción y frivolidades, la desaparición de la prensa de opinión y el surgimiento de diarios populares que relatan la vida cotidiana de las clases trabajadoras, aunado a un amento de la publicidad.

La finalidad de esta propuesta es descubrir esas características en la prensa escrita costarricense que circuló desde 1870, cuando el periodismo se consolida en el país, hasta 1950 cuando se evidencia un cambio en la forma de hacer periodismo tras el ingreso de la televisión y del cambio de formato en las noticias emitidas por la radio. Para cumplir este objetivo, se revisaron todos los periódicos editados en el país durante esos años y se ubicaron contextualmente, con la finalidad de responder a la pregunta ¿cuándo nace el periodismo sensacionalista en Costa Rica y cuáles son las manifestaciones más destacadas?

\section{Los primeros pasos}

En Costa Rica, las noticias de sucesos -accidentes, muertes, robos, crímenes, etc.-, una de las formas periodísticas donde el sensacionalismo se evidencia con mayor claridad, irrumpen desde finales del siglo XIX (Núñez, 1980: 13) ${ }^{1}$, pero ya para la segunda década del siglo XX, ocupan espacios permanentes en los periódicos. 
Uno de los primeros en incursionar en el destaque de sucesos fue El Heraldo, Diario Republicano Independiente en 1892. Ubica en el centro de la segunda página del periódico una nota titulada "El niño muerto" y relata:

Hace un mes próximamente ocurrió en la tipografía de El comercio un caso triste, del cual hablaron con amargura los diarios de la ciudad. Francisco Mora, niño de 13 o 14 años fue estrujado por la cabeza entre dos planchas de una prensa á tiempo que el desgraciado se ocupaba en recibir las hojas impresas. No quedaba esperanza de salvación, el estrujamiento había sido horrible; saltaron los ojos fuera de sus órbitas y por una hendidura de la frente se descubría una materia semejante a la masa cerebral.... (El Heraldo, 1892:2).

Ciertamente se trata de una nota aislada, pues este tipo de noticias no es el común en ese periódico, pero la frialdad del relato ya evidencia el inicio de una nueva forma de exponer los hechos, para impactar en los sentimientos de los lectores.

Para entonces, la mayoría de la población costarricense pertenecía a una clase media rural heterogénea, poseedores de pequeñas fincas que trabajaban con mano de obra familiar y que además de café, cultivaban lo requerido para su subsistencia. Algunos, cierto, eran jornaleros ocasionales, sin tierra -buena parte de ellos la habían perdido en las transacciones con los beneficiadores y exportadores de café- que se ubicaban en la cúspide de la pirámide social. En ese momento, la educación era vista como una posibilidad de ascenso social para los hijos.

En 1900, los impresos tenían un tiraje pequeño, los diarios que editaban más ejemplares no superaban los 2000 y suponiendo que cada uno es leído por dos personas por lo menos, el número de consumidores en el territorio es relativamente reducido, $2 \%$ del total de habitantes. Esta escasez de lectores se puede deber en parte a que las publicaciones se imprimían y distribuían mayoritariamente en las ciudades principales, en particular en San José, donde habitaban, en 1900 cerca de 25.000 personas (Censo Municipal, 1904). Además, es preciso considerar que buena parte de la población del país era analfabeta, en ese momento, poco menos del $50 \%$ (Censo de Población, 1982) de las poblaciones mayores de 10 años, en las zonas urbanas, lo que indica que el contenido del periódico podría ser difundido más a través de la oralidad, como ocurrió en Costa Rica desde 1833 hasta 1900, que por la lectura directa.

Hacia la segunda década del siglo XX, un sector de la población se convierte en asalariado de los incipientes talleres e industrias que se ubican en la capital. Era un grupo numéricamente reducido ( $9 \%$ de la población) pero sí capaz de organizarse para

relatos de crímenes, robos y otras fechorías... [los hermanos Briceño] contaron con el periodista español Segundo Ispizúa, especialista en el sensacionalismo". 
obtener mejoras en sus condiciones laborales. Estos grupos se manifestaban, además de las huelgas y las protestas públicas, a través de los periódicos. Incluso crearon sus propios espacios impresos, financiados por los miembros de las asociaciones o sindicatos y practicaron la lectura en voz alta de los periódicos, de modo tal, que éstos textos alcanzaban a la población iletrada.

Los periódicos, entre tanto, tenían poca demanda en una población diminuta. No será sino hasta después de 1920 cuando empiece un nuevo campo para el periodismo nacional. Fue entonces cuando se preocuparon por ganar lectores. Ya la prensa había cambiado después de la Primera Guerra Mundial (Vega, 2014). La Gran Guerra fue un acontecimiento mediático de magnitudes nunca vistas en Costa Rica. Los consumidores de periódicos demandaban las noticias y seguían los acontecimientos con fervor a través de la prensa. Los periódicos debieron satisfacer las demandas e innovar en la forma de presentación de las informaciones. Al finalizar el conflicto las diferencias se evidenciaron en el manejo de los titulares y la ubicación del foco noticioso: se privilegian los sucesos referentes a asesinatos, muertes extrañas, accidentes, hechos delictivos de diversa tipología. La contienda había enseñado a los comunicadores que la muerte y la barbarie de la guerra atrae lectores. Dejó también la enseñanza de no confiar en una sola fuente, algo que se aplicará a partir de entonces en un nuevo género periodístico: el periodismo interpretativo o de investigación.

Tras la guerra, los escritores de periódicos ensayaron con nuevos géneros periodísticos: la entrevista, el reportaje, la crónica -aunque mezclaban géneros informativos y de opinión-, y la noticia. La prensa intentó ser calificada de veraz en sus páginas, por eso acudieron a referir los despachos de donde extraían la información; hubo una preocupación por la inmediatez.

Para elaborar este nuevo periodismo, se hacía preciso contar con más y diversas fuentes, lo que los lleva a averiguar la información más allá de los rumores: buscan documentación de respaldo, relatan crónicas vivenciales, usan la entrevista, entre otras. Crean nuevas secciones para orientar al lector y llegar a nuevos públicos.

Este nuevo escenario favoreció la consolidación de un periodismo más sensacionalista sin alcanzar los detalles del periodismo que se practicó en los Estados Unidos desde el siglo XIX. 


\section{El primer intento sensacionalista}

Ya antes de la Gran Guerra, El Noticiero, Diario de la mañana, había incursionado en un periodismo que apela a las emociones humanas. Sin denominarle "sucesos" como sección, mantuvo una página diaria intitulada "crónica" donde se intercalaron noticias de sucesos con otros relatos referentes a temas políticos o económicos e incluso culturales. Eran notas cortas.

Por ejemplo, el 20 de mayo de 1904 se exhiben en ese impreso asuntos muy diversos: una exposición de espejos venecianos, la necesidad de un médico en una comarca lejana de la capital, la graduación de un grupo de médicos, la fiebre amarilla en San Mateo de Alajuela, la divulgación de una revista, experimentos médicos, robo perpetrado por un sirviente en casa de Ramón Alvarado, el accidente de un "carretonero de apellido Jiménez, que cargaba en su carretón unos bultos de mercaderías de una casa de comercio (cuando) ... al cargar uno de los bultos se vino encima uno de los que ya había colocado y le lesionó fuertemente la cabeza, derribándolo al suelo. Algunos compañeros de oficio le prestaron auxilio" (El Noticiero, 20-05-04, p. 3). Continúa una noticia sobre un pleito a "paraguazos" cerca del teatro nacional entre dos jóvenes de sociedad (es decir, pertenecientes a familias adineradas), acusaciones contra un periódico, el horario de correos, la venta de ladrillos, la aprehensión de contrabandista que manejaba un depósito de aguardiente, publicaciones injuriosas del Liceo de Costa Rica, nombramiento de un mandador para la limpieza de calles, el arreglo del tranvía, reunión en el colegio de abogados, un pleito entre dos jóvenes artesanos que acabó con unas copas que ambos tomaron juntos en la pulpería ubicada al frente de donde tuvieron el altercado; la renuncia del director del Liceo, una feria para recaudar fondos para el templo, una acusación del periódico La República, suspensión de una obra de teatro a causa de la lluvia y como nota estelar, tras el subtitular de "servicio de la noche", se pormenoriza una información que en resumen, detalla que Ismael Cano se presentó en casa de Vicenta Rojas y fue recibido malamente por los dos hijos de ella quienes dieron tremenda paliza a Ismael, a vista y paciencia de espectadores del barrio. La señora Rojas abofeteó a una vecina que opinaba que no era justo pegar entre dos a Ismael.

Como se observa, todas las notas cortas que conforman la columna se refieren a asuntos cotidianos que los diversos grupos sociales los reconocen como parte de su diario vivir. La última en particular, atiende un tema que despierta el interés de los sectores populares pues se trata de una práctica recurrente en la Costa Rica de ese momento. Por lo general, las diferencias conducían a golpes e incluso al uso de armas de fuego o armas blancas. 
Las crónicas se vuelven cada vez más crudas, frecuentes y éstas a su vez, ocupan más espacio en el periódico conforme pasa el tiempo. Por ejemplo, el 2 de mayo de 1907 se relata con especial detalle, en El Noticiero Diario de la mañana, el crimen de un hombre en Aserrí, cuya edad no se menciona pero en cambio se hace especial énfasis en la edad del homicida -14 años-, no el supuesto criminal pues la noticia lo califica como asesino desde el título:

"Espantoso y abominable crimen cometido por un niño de 14 años de edad"

El homicida robó una suma de dinero a su víctima.

Ayer mañana tuvimos conocimiento de un horroroso y abominable crimen, cometido por un niño de catorce años de edad en el cantón de Aserrí, hecho del $q^{\prime}$ (sic) pedimos informes urgentes á nuestro corresponsal en aquella localidad, quien nos contestó inmediatamente en la siguiente forma:

Aserrí, Mayo 1으 (Recibido á las 2 y 30 p.m.)

A ... Director "Noticiero".

El domingo último, como á la 1 p.m. tuvo conocimiento el señor Jefe Político de este cantón por el Agente de Policía de San Ignacio, de haber sido encontrado muerto en un rancho, el vecino de aquel pueblo Juan Godínez, quien presentaba una herida en la espalda. Inmediatamente se constituyó el Señor Alcalde de el lugar del acontecimiento.

Levantó la información correspondiente para esclarecer el espantoso crimen. De la sumaria se deduce que el autor del asesinato fue el joven de catorce años de edad, Rafael Rivera Quirós, niño que hace pocos días fue apresado por la Policía de esta villa por haber cometido un robo de consideración. El asesino, después que mató a Godínez, le robó el dinero que portaba. El hecho ocurrió en el lugar denominado "El Tablazo._Corresponsal.

Como ocurrió el hecho

Godínez se encontraba en su casa, dicen que durmiendo, cuando llegó el pequeño asesino y disparándole un tiro de revólver por la espalda le dejó muerto en el acto. Rivera Quirós se arrojó inmediatamente sobre el cadáver de Godínez apropiándose del dinero que encontró en sus vestiduras y desapareciendo inmediatamente de aquel lugar.

Cuando el cadáver de Godínez fue encontrado, ya se hallaba putrefacto. Trasladado que fue á la Alcaldía de Aserrí, todos los vecinos de aquella localidad acudieron á verlo, entre los que se encontraba el niño asesino quien no se 
inmutó siquiera al contemplar el cuerpo rígido, frío, ensangrentado de su víctima. Desde el primer momento recayeron todas las sospechas sobre Quirós quien fue detenido provisionalmente.

En su primera declaración negó rotundamente haber sido él el autor del crimen, pero al tercer día confesó de plano su culpabilidad haciéndose responsable del hecho que se le imputaba.

Rivera Quirós no niega que él traidoramente mató á Godínez para robarle, y relata como llevó á cabo el crimen con sangre fría y un colorido tal que da miedo. El criminal pasará en estos día á la Cárcel de esta ciudad á las órdenes del Juez 2ㅇ del Crimen. Entonces tendremos oportunidad de reportearlo" (El Noticiero Diario de la Mañana, 2-5-1907, p. 3.).

El periódico condena, sin juicio previo al joven Quirós (condena mediática). Las declaraciones de éste, aceptando finalmente la culpa luego de tres días de interrogatorio, no se explica, es decir no responde a la pregunta ¿qué lo hizo cambiar de idea y aceptar su delito? El reportero construye una imagen del chico que no deja lugar dudas de su crueldad: hirió mortalmente por la espalda a Godinez, a sangre fría, participó del entierro simulando como uno más de los dolientes y confiesa su crimen, con detalle y sin inmutarse. Por la forma como está escrito y por los detalles que privilegia, el autor de la nota destaca entre líneas expuesto el cinismo y el sadismo del criminal.

La muerte y en especial, las muertes violentas resultan para los redactores de El Noticiero un tema permanente. En la búsqueda del morbo y la invasión de la intimidad, dos características del sensacionalismo, el 17 de mayo de 1908, El Noticiero detalla el momento en el qué el cuerpo Francisco Arguedas, quien se había suicidado con arma de fuego, es entregado a su madre. Se transcriben una a una sus palabras para concluir que la señora “...cayó atacada dejando consternados á todos los allí presentes". De esta manera se aprovecha del dolor y de los malos momentos de las personas para capturar a la audiencia.

El suicidio era un tema muy frecuente. En 1904 se relata cómo el panadero Apolinio Marín, intenta suicidarse cortándose el cuello. Los panaderos formaban parte del conjunto de obreros y artesanos asalariados de San José. Pertenecen a los sectores populares, y se reconocen a sí mismos como parte del grupo -identidad-. Ellos en particular jugaron un papel preponderante de la huelga de 1920 en procura de mejorar sus condiciones laborales demandando una jornada laboral de 8 horas. La crónica es detallada. Inicia pormenorizando las actividades realizadas por Apolinio:

En la mañana de ese día [el día del suceso], Marín estuvo trabajando hasta las diez, hora en que salió para ir á almorzar; pero, según cuentan varios amigos, se tomó unas cuantas copas que lo descompusieron un tanto. Como á las $12 \mathrm{~m}$. Se 
dirigió á su casa, [especifica la dirección con pormenores, se trataba de un barrio popular en el corazón de la capital] situada en la Calle 15 Sur y allí se recostó un rato en su cama levantándose enseguida para encerrarse en su cuarto. A los pocos momentos su esposa oyó unos gritos y entró á la habitación encontrando á su marido tirado en el suelo bañado en sangre, [la mención de la sangre es recurrente para provocar impacto emocional en el público] pero aún daba señales de vida. Inmediatamente fueron llamados los doctores Toledo é Inkseter, quienes le hicieron las primeras curas y le suturaron las heridas que se había producido en el cuello. Estas no fueron de mucha consideración debido á que el cuchillo que empleó no tenía suficiente filo, y á que, afortunadamente, no logró interesar ninguna arteria. Las heridas que se infirió fueron tres; [refiere pormenorizadamente a las heridas]una en toda la extensión de la garganta y dos pequeñas debajo de ésta. Enseguida el herido fue trasladado al Hospital, y si se sujeta al régimen prescrito, dentro diez días sanará.

Marín, como dejamos dicho, es casado y tiene una regular familia, que sostiene desahogadamente, gracias á su dedicación al trabajo y á sus excelentes aptitudes.[De esta manera lo ubica dentro del grupo de la gente común y continúa detallando que] Ha logrado, además, reunir un poco de dinero, que empleó en la compra de una casa. Entre todos sus compañeros, amigos y relacionados, Marín pasa como hombre formal, laborioso y honrado, lo que le ha valido la estimación y buena fama de que goza de parte de todos cuantos le conocen y de sus jefes" (El Noticiero, 25-4-1904, p. 3).

En 1910, la nota titulada "Herido a puñal. Antecedentes que promovieron el ataque" es uno de los ejemplos más evidentes de la apelación que es típico del sensacionalismo, a los asuntos próximos a la colectividad, extraídos de su cotidianeidad y por ello, de mayor realismo. En esa oportunidad se refieren a que el sastre de 27 años, vecino de barrio de la Dolorosa, en el centro de la ciudad de San José, llamado Gonzalo Naranjo Guevara, había construido un rancho junto con otros compañeros para resguardarse de los incesantes temblores de tierra que estaban acaeciendo tras el terremoto que destruyó la ciudad de Cartago en mayo de 1910. Tuvo un disgusto con uno de ellos y como era costumbre, se dieron de bofetadas, ambos bastante borrachos, y el compañero lo hirió con un puñal en el brazo izquierdo. "El Médico del Pueblo, doctor Nazario Toledo, reconoció á Naranjo y dictaminó que la herida que éste sufre sanará en quince días, caso de que no sobrevengan complicaciones..." (El Noticiero, 20-5-1910, p. 4). De modo tal que se construye una noticia de un suceso que no lo era.

En 1919, La Prensa Libre, un vespertino perteneciente a la sociedad Clare y Jiménez, dueños también del periódico La Información(Gutiérrez, 1989, 100), el de mayor circulación en el país, mantiene una columna denominada "A GRANEL" donde se 
dedicaban a exponer notas cortas de sucesos. Están separadas por un espacio y se ubica siempre en la página 4. El 3 de enero de ese año, por ejemplo se exponen las siguientes informaciones.

Avelino Guevara le causó una herida en la cara a Santos Rivera, con arma cortante. Tardará nueve días en sanar.

\section{$(\ldots)$}

Roberto Hernán B. Le dio de golpes y le causó conturaiones (sic)a Carlos Nelson; ocurrió esto a las 7 y 25 p.m. de ayer. La herida es circular a concavidad superior, de tres centímetros de largo e interesó el tegido (sic) cutáneo y subcutáneo en la región suborbitaria (sic) izquierda.

Según el dictamen médico el ofensor usó de manopla.

\section{$(\ldots)$}

A las ocho y media de hoy fue capturado un cado, ladrón de bombillas, en el interior de la fotografía del señor Sotillo Picornell. Este pájaro penetró al local con el pretexto de hacerse un retrato y en un descuido se echó cuatro de las indicadas bombillas a la bolsa. Al asentarle el traje el operador para tomar una instantánea le hallaron lo robado.

Ya está entre rejas el aligero, que es de apellido Aridón.

\section{(...)}

Gil Coto y Gonzalo de J. Ramírez destrozaron la puerta de la casa de Marco Aurelio Rodríguez, así como las ventanas de la habitación de Nemesio Estrada Mélida a las tres y media de la mañana.

Atropelló con un auto Guillermo Salazar Soto a Juan Salazar Romero a las 2 p.m. La policía tomó nota del desaguisado.

A Antonio Monge Reyes le robó con tal presada un anillo liso de oro, de matrimonio y una pulsera de plata (La Prensa Libre, 3-1-1919, p. 4).

Como se observa, se trata de notas emanadas de la sección de policía, que para entonces ya es una de las fuentes más apreciadas para extraer sucesos que el periódico se encarga de vender utilizando un leguaje coloquial, sencillo que apela a la jerga que usa la gente común.

En 1922, La Nación, destaca con titulares de primera plana dos notas: "Una intoxicada por equivocación" y "Accidente automovilista". La primera indica que por error "...se envenenó la señorita Clemencia Soto, de 14 años de edad. Es el caso que con la 
sirvienta Domitilla Villalobos, la madre de aquella niña, doña Enriqueta Uribe de Soto, mandó a comprar sal de Glanber, para administrar una dosis a su simpática hijita. Sea porque la doméstica se expresara mal o porque el boticario no entendiera, en vez de sal de Glanber se le dio a la sirvienta carbonato de soda, llamado también sal de lavar..." el final de la nota indica que la señorita se sanó con prontitud. Llama la atención la atribución de la culpa a la señora Villalobos, perteneciente a uno de los sectores excluidos de la sociedad.

La segunda señala que "a consecuencia de un accidente automovilista falleció esta mañana el joven Guillermo Mora, de 20 años de edad, chofer y vecino de San Pedro de Montes de Oca..."(La Nación. 2-1-1922, p.1).

De esta manera los individuos más comunes son elevados, por decisión de la prensa, a la categoría de figuras públicas. En esas páginas los lectores, de muy diferente extracción social, se podían ver reflejados, en otros términos, la separación entre la esfera pública y la privada, una conquista de la modernidad, es fracturada al explotar como noticia cualquier historia relativamente dramática de carácter personal o familiar.

\section{Un sensacionalismo más evidente}

Cuando las condiciones técnicas lo permitieron, los medios impresos usaron los titulares destacados, al inicio de la portada y resaltados con negro, además del uso exagerado del texto. El 4 de marzo de 1936 Novedades, un periódico de intereses generales, llama la atención de su público con la portada que se expone en la ilustración 1. Este es un periódico barato, se vendía a cinco céntimos cada ejemplar, tiene en el caso del ejemplo, un conjunto de fotografías en las que destaca un hombre sosteniendo una serpiente acompañado de varios espectadores colocados en segunda plana y una mujer, con traje de baño, leyendo un diario. Esta última es, para la época, un atrevimiento. En el pie de foto señala que se trata de "una linda y guapa bañista en la hermosa playa de Puntarenas, leyendo un ejemplar de nuestro colega LA TRIBUNA" (Novedades, 4-3-1936, p.1) 


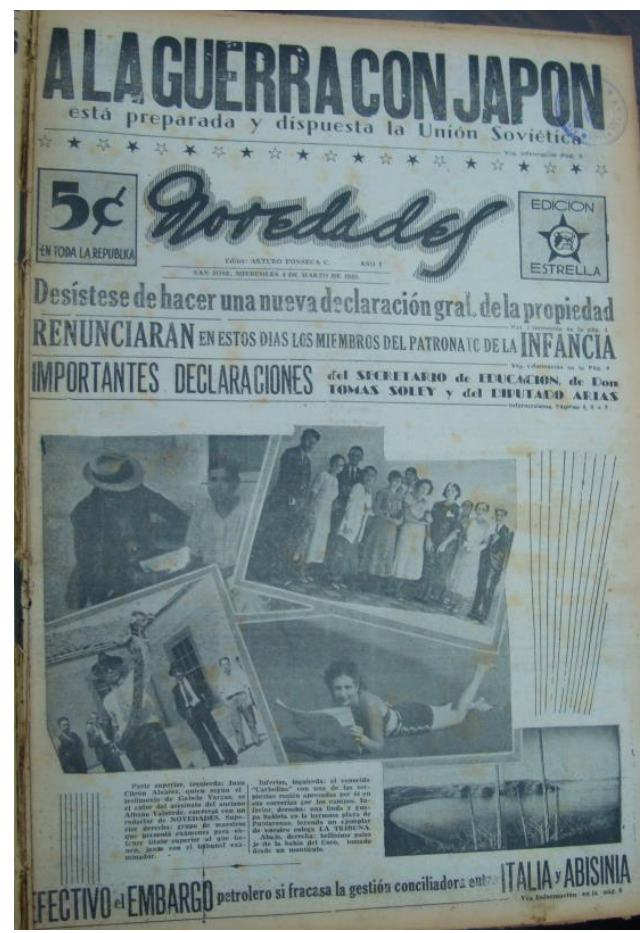

Ilustración1: Novedades, 4-3-1936, p. 1.

Última Hora, era un periódico de circulación nacional y perteneciente al Partido Republicano, que no tiene una intención sensacionalista evidente pero sigue la corriente de sus homólogos en el destaque en negro y en mayúscula de los titulares que le interesa enfatizar (Véase ilustración 2). En otros términos, la corriente que se impone es la de llamar la atención de los clientes a través de titulares no solo en mayúscula y en un negro más intenso sino con títulos sugestivos. Por ejemplo, el 31 de mayo de 1943 en el diario Última Hora se publica en la segunda página una nota titulada "Se repite el caso de la bella durmiente" reseñando que la madrastra de una chica de nombre Herminia, se enamoró del novio de esta y para seducirlo, decidió dormir a la joven "con una fuerte dosis de Dormitol. El joven que sospecho la maniobra, logro despertar a su adorada y todo terminó como en los cuentos de hadas" (Última Hora, 31-5-1943, p. 2). La nota acaba indicando que ambos jóvenes se casaron y esperan tener muchos hijos, al mejor estilo de los cuentos de hadas. 


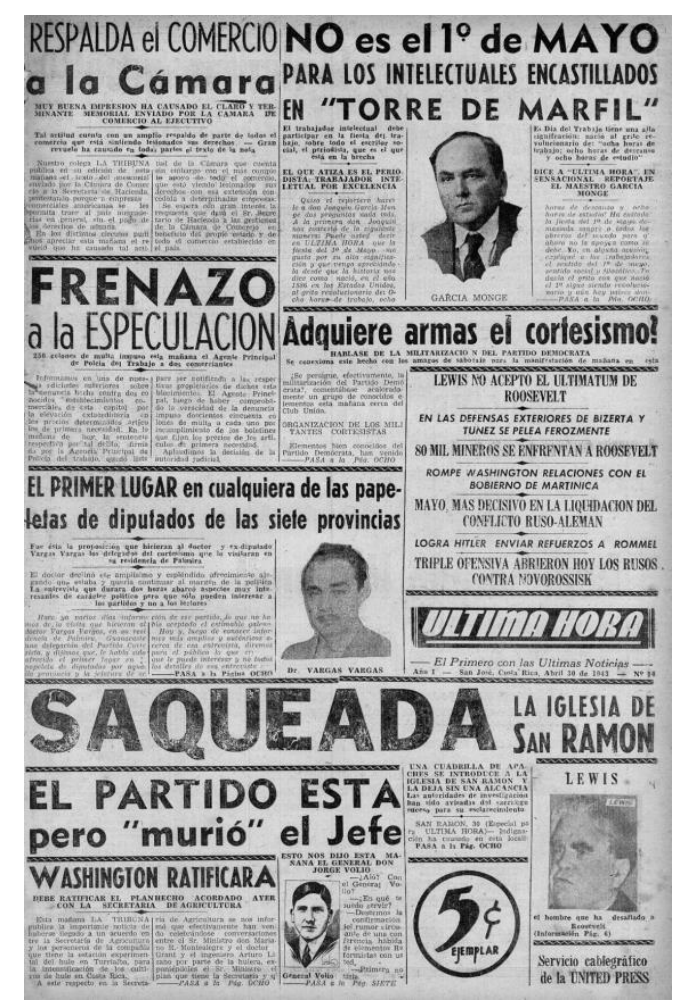

Ilustración2: ÚltimaHora, 30-4-1943, p. 1.

Una de las características del periodismo sensacionalista que se desarrolla en Costa Rica es el uso de palabras que despiertan las emociones: pavoroso, desgarrador, hechos de sangre, tragedia, etc.

En la nota de Última Hora, de abril de 1943 se evidencia este uso: un hombre "agredió a machetazos", "atacó a puñaladas o a cuchilladas", "clavándole repetidamente el puñal en la cara y en el estómago".

\section{El primer "pasquín" La Hora}

El 13 de marzo de 1933 sale por primera vez el diario "La Hora" dirigido por el intelectual costarricense de padres españoles José Marín Cañas. Se trata de un tabloide de 8 páginas, con 5 columnas y 14 pulgadas de altura, ensayó lo que Marín Cañas afirma en sus memorias, un nuevo tipo de periodismo "de mucha roña y escaso vuelo, que se vendía a cinco céntimos" (Marín, 1981, 137).

El Diario de Costa Rica, el más importante de la época, era el dueño de este periódico que la gente denominaba "pasquín" pues consideraba que trataba de asuntos sensacionalistas cuya credibilidad se ponía en duda. "Pasquín sustituía la palabra "mentiroso". 
En este diario se combinan el sensacionalismo y la ironía con el humor. Una forma de expresión del sensacionalismo muy local. Por ejemplo en el primer número, en la página 6 destaca tres titulares que evidencian esas características:

Rubén Murillo fue detenido porque se dedicaba a la tarea de pedir ropa para limpiar y se olvidaba de devolverla.

Víctor Flores descansa en la oficina de detectives, purgando el pecado de haber requerido unos sombreros que no eran de su propiedad. Afirma que su único objeto era obligar a los dueños a llevar la cabeza bajo el sol, con lo que se les quitaría la calvicie.

Miguel A. Castro sostiene que si él se alzó con un serrucho ha sido porque quería arrancar del instrumento las notas melodiosas de un fox de moda. El dueño del serrucho, que es carpintero, lo denunció y dijo que para estudiar música sería mejor que se comprara un violín, con tanto músico desocupado como hay ( $L a$ Hora, 13 -5-1933, p. 6).

La Hora era redactada por tres de quienes llegarían a ser de los literatos más destacados de Costa Rica en aquella época: Adolfo Herrera García, Abelardo Bonilla y el director del medio, Marín Cañas ya mencionado.

Su trabajo no fue sencillo aunque "reíamos más de lo que llorábamos" (Marín,138). Sus horarios de almuerzo nunca eran los mismos, cuando lograban comer. Trabajaban sin horario "lo mismo en el día que en la noche, y hasta las altas horas de la fría amanecida". Su salario era precario, escasamente alcanzaba para cubrir su alimento y su abrigo. La publicidad del periódico tampoco era copiosa y aunque se vendía bien, a pregón y por suscripción, no generaba gran ganancia en particular porque estaban empeñados en mantener el precio de cinco céntimos.

Al ser un periódico barato, se convirtió "por primera vez, [en] la dieta de los obreros, incapacitados para gastar más de un cinco por leer un periódico". Esto significa que se convirtió en un impreso apetecido por los obreros, como ocurrirá luego con el periódico “Extra” que nacerá a finales de los años de 1970.

Fue un diario que circuló por más de cuatro décadas alcanzando un tiraje record de 18.000 ejemplares. Según su director "agrandamos como se ve, el campo consumidor de periódico, por el precio. Alborotamos el cotarro, por la audacia y la travesura de los redactores. Nos burlamos hasta de nosotros mismos, y no falta quien diga que desde entonces cambió la facies de los periódicos nacionales, hasta nuestros días." (Marín, 140). En sus últimos veinte años trataron de cambiar su contenido incluyendo obras literarias en cada edición, incluso se publicaron novelas completas por capítulos, obras catalogadas por los expertos de gran calidad. Aun así "no pudimos quietarnos de encima nunca el calificativo vergonzoso y quemante de "pasquín" (Marín, 140). 


\section{Los amarillistas}

El uso del color llegó a Costa Rica hasta 1973. En esa oportunidad La Nación, el principal periódico de Costa Rica en ese entonces, "adquirió e instaló una nueva rotativa del fabricante Harris Cottrell, una prensa de impresión offset que permitió agregar color a los periódicos y suplementos. El 15 de mayo de 1973 se publicó un suplemento de historietas a color, por primera vez" (www.Grupo Nación.co.cr).

Tan tardío como en 1946, el diario La Nación, recién creado, mantenía una sección de ocio que publicaba diariamente. Contenía el crucigrama y tiras cómicas que se mezclaban con noticias de diversos tipos y que además se rodeaba de anuncios publicitarios (véase Ilustración 3). Paralelamente, los periódicos desde la década de 1930, mantenían una sección deportiva donde el fútbol era el más destacado. Estas secciones fueron creciendo con el tiempo. Si al inicio se les otorgaba una página, al avanzar la década de 1940 se dedicaban dos o más páginas.

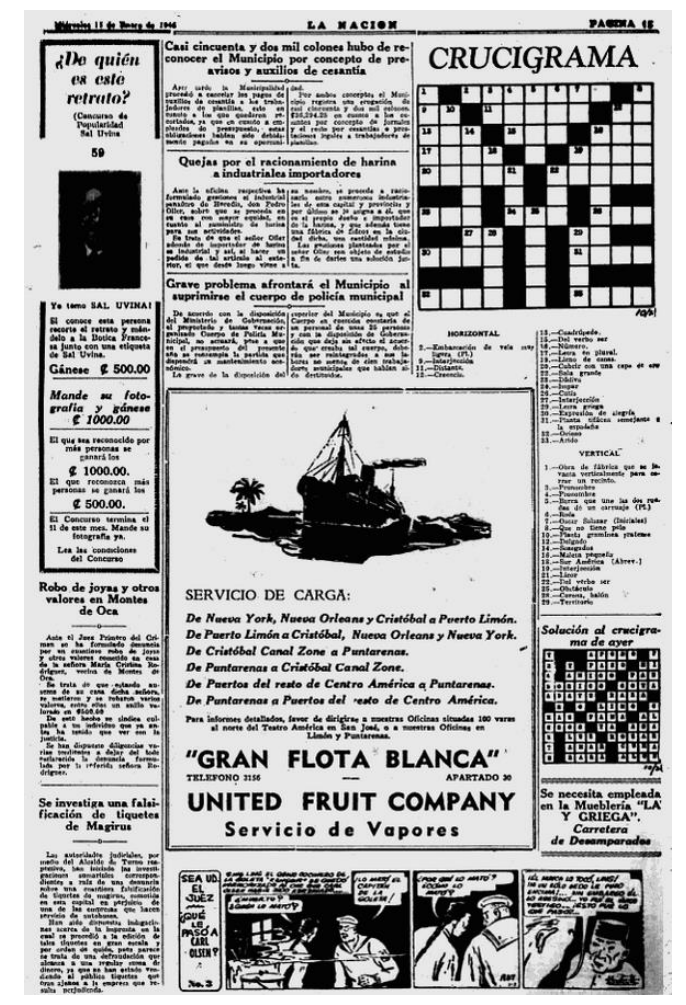

Ilustración 3: La Nación, 11-3-1946

Debieron pasar varias décadas para que el amarillismo se iniciara en Costa Rica. En 1978 se editó por primera vez un periódico cuyo objetivo era la irreverencia y la venta de la noticia roja, el Diario Extra. Con grandes letras rojas, con frases chocantes y distorsionando la noticia, este periódico se convirtió en el de mayor venta en el país. Como es de esperar en este tipo de prensa, el rojo es el color que destaca el título. Los cuerpos de las personas que mueren de manera violenta (véase ilustración 4), los 
rostros destrozados y las curiosidades chocantes: un animal o persona con dos cabezas o con dos cuerpos, los trozos de carne y hueso, etc.
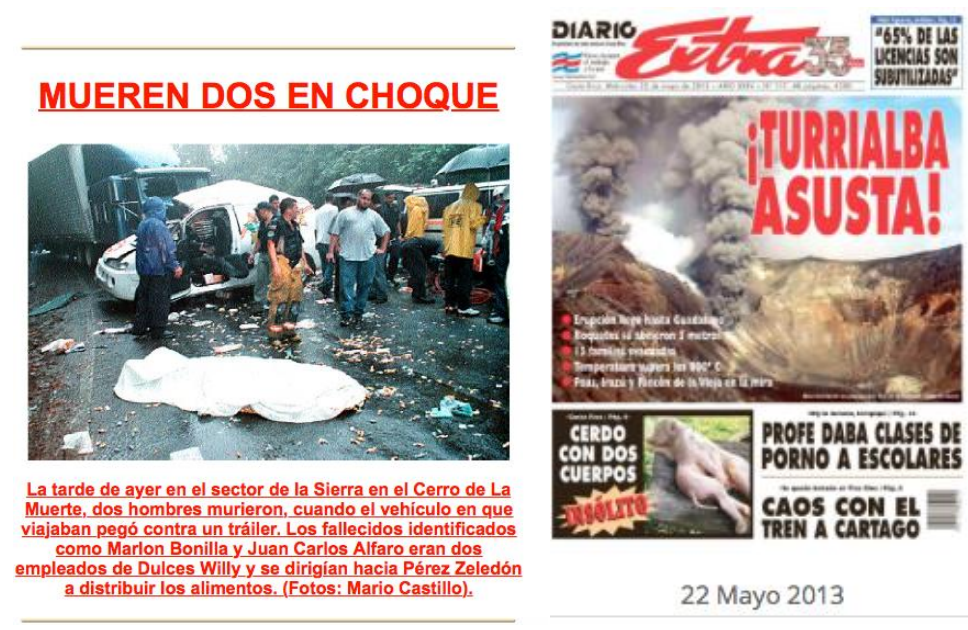

Ilustración4: Diario Extra: 10-3-2003

Aduciendo que la información es de interés público, se irrespeta el dolor ajeno y se viola la privacidad y la intimidad. En particular con la presentación de mujeres semi desnudas (véase ilustración 5), se explota la imagen o los atributos físicos de la persona como mercancía, mientras se reproducen los estereotipos y se satura de contenidos discriminatorios.

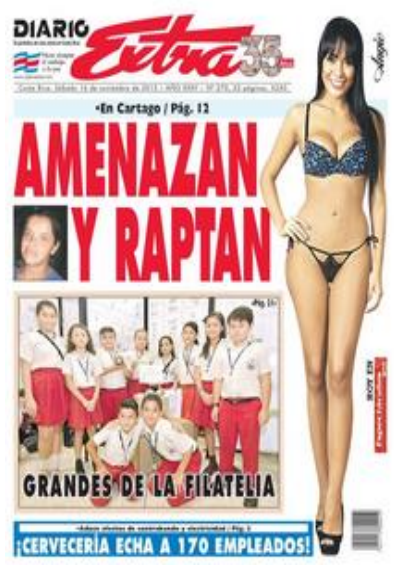

Ilustración5: Diario Extra, 15-10-2013.

También los menores de edad son víctimas de estos tratamientos periodísticos. No hay respeto alguno por su condición.

Extra presenta un culto al morbo que ha calado en la población y que incluso motivó a la empresa "Grupo Nación S.A.", la más grande del país, dueña de varios medios y de al menos 4 periódicos de circulación nacional, a lanzar el 20 de noviembre del 2006, La Teja, un diario que compite con Extra y presenta las mismas condiciones. Según afirman sus editores, alcanza los 730 mil lectores distribuidos en todo el país. A pesar 
de su fachada, los responsables aseguran que se trata de "un diario diferente, fresco, colorido, lleno de ingenio y humor, sin llegar al amarillismo. Busca interesar a la familia popular, dada la variedad de sus temas y promociones. Además, pretende recompensar con muy buenas promociones a sus lectores" (www.lateja.co.cr).

Destaca los titulares distorsionados, usa con frecuencia palabras violentas, no respeta códigos éticos, explota la desnudes femenina, entresaca de las noticias la morbosidad que implique a personas con cargos públicos.

\section{CONCLUSIÓN}

El periodismo sensacionalista fue tardío en Costa Rica con respecto al desarrollado por la prensa estadounidense. Es posible que su estrecha relación económica, política y cultural con Europa, particularmente con Francia, Inglaterra y España, favoreciera que se emulara y se aprendiera de la prensa europea y se imitara su forma de hacer periodismo.

No será sino hasta después de la Primera Guerra Mundial que la influencia estadounidense es decisiva en el país, fundamentalmente en la economía pero también en la cultura. Cambiaron los patrones de consumo: el vestido, la alimentación, los menajes de casa, los autos, entre muchos. Cambiaron los planes de estudio en Escuelas primarias y secundarias, el inglés se convierte en la segunda lengua y se mudan las formas de hacer periodismo. Los periódicos estadounidenses se convierten en el ejemplo. Es quizá eso lo que influye para que el sensacionalismo nazca con las características de la prensa estadounidense después de 1920 y de manera contundente luego de 1978, cuando la globalización inicia su proceso de inserción definitivo.

\section{Referencias bibliografía:}

Censo de Población, (1892). Dirección General de Estadística y Censos, San José: Imprenta Nacional.

Censo Municipal, (1904). Dirección General de Estadística y Censos, San José: Imprenta Nacional. 
DIARIO LA PRENSA LIBRE (en línea). Disponible en Internet (19-6-2015): www.mediatico.com/es/goto.asp?url=1129.

GARCÍA, G. (1999): "La conformación de la moderna prensa informativa (1848-1914)", en Gómez, J.; Gómez y Marín, E. (editores), Historia del periodismo universal Madrid, Editorial Síntesis, pp. 65-99).

GRUPO NACIÓN. (En línea). Disponible en Internet (5-6-2015): http://www.gruponacion.co.cr/?q=historia.

GUTIÉRREZ, P. (1989): 100 años de historia a través de la Prensa Libre, San José, Impresora costarricense S.A.

LA TEJA. (En línea). Disponible en Internet (2-6-2015): www.lateja.co.cr.

MARÍN, J. (1981): Valses nobles y sentimentales, San José, Editorial Costa Rica.

MOLINA, I. (1999). "Explorando las bases de la cultura impresa en Costa Rica: la alfabetización popular (1821-1950)", en: Vega, P. (compiladora) Comunicación y construcción de lo cotidiano. San José. DEI, pp. 26-64.

NúÑEZ, F. (1980): Periódicos y periodistas, San José, Editorial Costa Rica.

SCHUDSON, M. (1978): Discoverinthe News. A social history of American News Papers, Estados Unidos, Farrar, Straus\&Giroux, Inc.

VEGA, P. (2013): “La guerra como espectáculo mediático. La prensa Centroamericana en la Gran Guerra (1917)" Revista Historia y Comunicación Social. Vol 18, Universidad Complutense de Madrid. 